\title{
Physical modeling of a fire with the use of the Froude number
}

\author{
Mateusz Zimny \\ The Main School of Fire Service, email: mzimny94@gmail.com \\ ORCID: 0000-0002-4466-7515
}

\begin{abstract}
Ever since the field of Fire Safety Engineering first came into existence, small-scale (model scale) fire tests were the source of much valuable information about the phenomena occurring during combustion. Over the years, several computational methods to determine the criteria for the similarity of fires on both a real and small geometric scale have been developed. The purpose of this article is to present a method of performing fire tests on a model scale using the Froude number. The basics of scaling, similarity conditions that must be preserved, ways of describing fire phenomena, as well as methods of calculating fire parameters from the real and model scale have been discussed. An example of physical tests with the use of reduced research models is also presented. What is particularly emphasized is how important these types of experiments are and what responsibility rests with the people who carry them ouvol. The motivation to conduct research is the safety of people who reside in buildings with fire protection based on model scale test.
\end{abstract}

Keywords: Physical modeling, Froude Number, fire tests.

\section{Introduction}

Fire is an uncontrolled phenomenon during which large amounts of heat are emitted, together with the production of toxic combustion products. Although this phenomenon has been the subject of research for many years, the scientists dealing with this issue are yet to fully comprehend the complexity of the combustion process. The continuous development of new materials used in everyday life, as well as other ways to use those already known further deepen this gap.

The constant need to update data requires the development of new fire experiments as well as the re-execution of those already carried ouvol. This approach also allows the validation of results already obtained using more accurate research methods [1], [2]. Undoubtedly, the best way to determine the course of combustion and the flow of smoke in a particular building would be to build it and then burn it completely - although even this does not guarantee success due to the lack of control over the ambient conditions (wind, temperature, humidity). Interestingly, real-scale (1: 1) fire experiments were and are still being carried out [3], [4]. Currently, however, fire tests on a 1: 1 scale are more often carried out for a specific element of interior design or furnishings, such as a desk, sofa or chairs [5]. The results obtained from individual experiments may bring us closer to real fires, but they do not provide a complete solution. Knowledge of the physical aspects of smoke flow (mass and heat) can be extremely helpful in determining the conditions in a building, for example during evacuation. The execution of this type tests for objects with a unique distribution and accessories is virtually impossible. Therefore, model scale research 
is used for such purposes. They allow to perform many variants of a given test with a few repetitions at a lower expenditure of time and financial resources [6]. Model scale studies do not have to be limited to one small model. Known cases of building a group of a dozen or so houses (on a scale of 1:3) to assess whether the fire will actually spread between buildings, as the theory assumes [7], appear in the literature on the subjects.

Other studies involved building a train model on a 1:2 scale. The effects of interior finish, number of windows or location of the stimulus initiating combustion were checked. Another method of approximating the conditions that may occur during a real fire are computer simulations [8], [9]. Nowadays, thanks to the almost unlimited access to significant computing power, the popularity of computational fluid dynamics (CFD) calculations is increasing. It is extremely important that these applications correspond to reality. Model scale fire tests are also performed to validate and verify these types of programs.

But how to relate the results obtained from the model scale test to reality? After years of research by scientists in the field of Fire Safety Engineering (IBP), methods of scaling and converting results from the model scale to the real scale have been developed [10]. This article focuses on approximating the methodology of scaling a physical fire modeling using the Froude number.

\section{Basics of scaling}

The complexity of the phenomenon of fire is still not fully understood. Currently, many analytical and computer methods for determining the combustion process are known. Still, full-scale physical tests are still the best and most reliable source of information. It is thanks to such research that new ones can be created, and the mathematical combustion equations used in popular computer models can be validated and verified [11], [12]. Despite the unquestionable advantages, conducting such an experiment requires a huge amount of time and money. Therefore, since the 1960s, in the field of Fire Safety Engineering in Poland and in the world, the methodology of testing on a model scale has been developing.

Conducting tests on a smaller scale is characterized by lower expenditure both in time and finances in relation to the real scale (1: 1). In that, it is possible to check how a given phenomenon would take place in an existing building object unavailable for such purposes. With the right amount of free space, materials and knowledge about the theory of scaling, a model of any building (e.g. warehouse, shopping mall), structure (e.g. road / railway tunnel) or any other space (e.g. forest) can be created and experiments can be conducted. With current tests comparing the results of tests on a scale model with the actual scale [13] all subsequent tests may be conducted with greater accuracy and in an easier way. However, to make this possible, an appropriate method of converting the analyzed parameters should be used. In the scaling technique using dimensionless similarity numbers, the starting point is Buckingham's Theorem [14] also known as "Pi theorem" (П theorem).

\section{The Buckingham Theorem}

"Each function of $\mathbf{n}$ dimensional parameters $\mathbf{a}$, of which $\mathbf{k}$ has basic dimensions, can be represented as a function of $\mathbf{n}-\mathbf{k}$ dimensionless parameters of type $\Pi$. If the dimensionless parameters $\Pi$ are identical, the phenomenon will occur identically despite the differing parameters of type $\mathbf{a}_{\mathbf{i}} . "$

The above theorem (Theorem $\Pi$ ) is based on the principle of dimensional unity. It states that if indeed the equation expresses the proper relationship between variables in physics, this process will be uniform in dimension. Each of its parameters will have the 
same dimensions [15]. Thus, a dimensionally homogeneous equation containing $\mathbf{n}$ mathematically variables:

$$
Z=f\left(Z_{1}, Z_{2} \ldots Z_{n}\right)
$$

can be written in dimensionless form:

$$
\Pi=\Phi\left(\Pi_{1}, \Pi_{2} \ldots \Pi_{n-k}\right)
$$

Formula (2) is very important for research conducted on a model scale. Since its derivation, it has ceased to be necessary to always study the functions of variables. It is enough that they are identified, which is a great help for scientists dealing with this topic. In addition, it is worth emphasizing that a change in the value of the $\Pi$ argument can be introduced by transforming even one of its arguments. With this, conducting experimental research is much easier.

\section{Characteristic numbers - the Froude number}

\subsection{Conditions of similitude}

We consider two phenomena to be similar if the value of the measured parameter on the real scale is proportional to the value of the parameter on the model scale. Such phenomena will be similar if the similitude of:

- geometric dimensions,

- physical properties,

- boundary conditions, and

- initial conditions

is maintained.

The purpose of physical tests is to obtain reliable results that can be used to determine the possible conditions occurring in a given facility during a fire. However, in order for the conclusions resulting from the experiments to be put into practice, the theory of similitude should be used. Based on the review of the available literature on the subject, three types of similitude have been identified [16].

Geometric similitude - consisting in maintaining similarity of dimensions and shapes in the model and real objects. When the linear dimensions of the original and the model are proportional to each other, then the original and the model are considered to be geometrically similar.

Kinematic similitude - consisting in maintaining speed fields between the model and the real objects. It occurs when the current line profile in the model and real flow are proportional to each other.

Dynamic similitude - consisting in maintaining one of two criteria:

- dimensional analysis resulting from the Buckingham theorem. It is necessary to know the physical quantities necessary to completely describe the phenomenon;

- analysis of equations defining a given phenomenon (without solving them) in model and real flow.

The use of any of the types of similarity mentioned above allows to obtain dimensionless similarity numbers (criterion numbers). 


\subsection{Modeling the described phenomenon using dimensionless functions}

Table 1 lists the variables that most often appear in dimensionless analysis related to the IBP domain.

Table 1. Dimensional relationships occurring in fire test. Source: Own study based on [15].

\begin{tabular}{llll}
\hline Relationship & Name of relationship & Interpretation & Application \\
\hline$\frac{\rho V l}{\mu}$ & Reynolds number (Re) & $\begin{array}{l}\text { inertia forces } \\
\text { viscous forces }\end{array}$ & $\begin{array}{l}\text { issues of fluid } \\
\text { mechanics }\end{array}$ \\
\hline$\frac{V}{\sqrt{g l}}$ & Froude number (Fr) & $\frac{\text { inertia forces }}{\text { gravity forces }}$ & free space flow \\
\hline$\frac{\Delta p l}{\rho V^{2}}$ & Euler number (Eu) & $\frac{\text { pressure }}{\text { inertia forces }}$ & $\begin{array}{l}\text { issues of pressure } \\
\text { differences }\end{array}$ \\
\hline$\frac{g l^{3} \beta \Delta T}{v^{2}}$ & Grashof number (Gr) & $\frac{\text { buoyancy forces }}{\text { viscous forces }}$ & $\begin{array}{l}\text { issues of fluid } \\
\text { mechanics }\end{array}$ \\
\hline
\end{tabular}

This article examines fire modeling methodology using the Froude number. This relationship is named after William Froude, a British civil engineer, architect and mathematician living in the 19th century. He became famous for his pioneering approach to ship design using a model scale.

The Froude number is the ratio of forces caused by the acceleration of a flowing particle (inertia force) to the force of gravity. This equation is of great importance when considering free flows. Mathematically, this can be written using the formula (3):

$$
F r=\frac{V}{\sqrt{g l}}
$$

The magnitude of the inertia force component (F1) along the current line can be expressed as:

$$
F_{1}=a_{s} m
$$

where: $a_{\mathrm{s}}$ is the amount of acceleration along the flow line for a particle with mass $\mathrm{m}$.

It is known from the particle motion studies that the particle lifting path is curved. The phenomenon of particle movement in the convection column is shown in Fig. 1.

The movement shown in Fig. 1 can be written as:

$a_{s} \frac{d V_{s}}{d t}=V_{s} \frac{d V_{s}}{d_{s}}$

where: $\mathrm{s}$ is measured along the lift path in the convection currents.

By writing the speed $\mathrm{V}$ and length $\mathrm{s}$ as dimensionless numbers:

$$
V \cdot s=\frac{V s}{V} \cdot s=\frac{s}{l}
$$




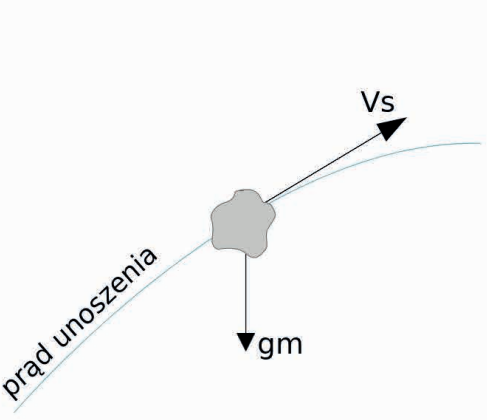

(a) Prąd unoszenia



(b) Prąd unoszenia w kolumnie konwekcyjnej

Fig. 1. Impact of gravity on the path of a moving particle. Source: Own study based on [14]

In equation (6) $\mathrm{V}$ and 1 represent, respectively, the characteristic speed and dimension (e.g. length), therefore:

$$
\begin{aligned}
& a_{s}=\frac{V^{2}}{l} V \cdot s \frac{d V \cdot s}{d_{s}} \\
& F_{1}=\frac{V^{2}}{l} V \cdot s \frac{d V \cdot s}{d_{s}} m
\end{aligned}
$$

The particle weight $\mathrm{F}_{\mathrm{G}}\left(\mathrm{F}_{\mathrm{G}}=\mathrm{gm}\right)$, so the ratio of inertia to gravity is such that the ratio of force $F_{1} / F_{G}$ is proportional to $V^{2} / g l$, and the square root of this expression $(\mathrm{V} / \sqrt{\mathrm{gl}})$ is called the Froude number.

$$
F r=\frac{F_{1}}{F_{G}}=\frac{V^{2}}{g l}=\frac{V}{\sqrt{g l}}
$$

\subsection{Physical modeling}

Equations of flow phenomena (e.g. water, smoke) are currently most often solved using computer programs designed to solve the equations of numerical fluid mechanics. However, there has always been a need to develop a method for mapping real-scale test. Model scale research is the simplest and most accurate. In the 1960s, Thomas [17] performed physical experiments using hot air. The 1970s abounded in model research, which was carried out using a mixture of kerosene and water [18]. In the 1980s, models filled with fresh water were used for this purpose [19]. Salt water with a higher density and the addition of dark pigment was used to represent the flow of smoke. These simple techniques allowed mapping of small-scale fire tests performed in full-size geometries, as well as verification of mathematical models known at that time. Currently, deterministic CFD simulations or stochastic calculations based on multi-simulations are used to predict smoke flow in rooms [9], [20]. A comparison of the older method using the water-filled model and the newer method of solving computer-based fluid mechanics equations is shown in Figure 2. 
a)

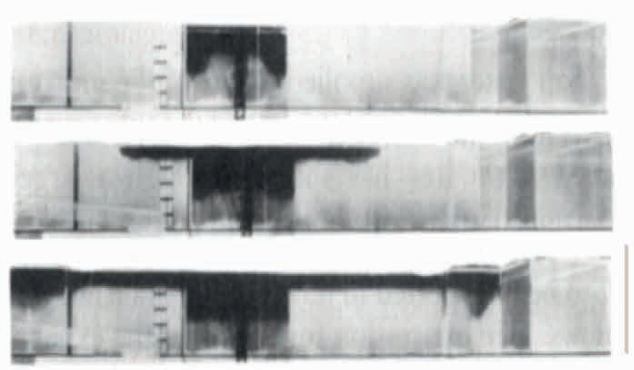

b)
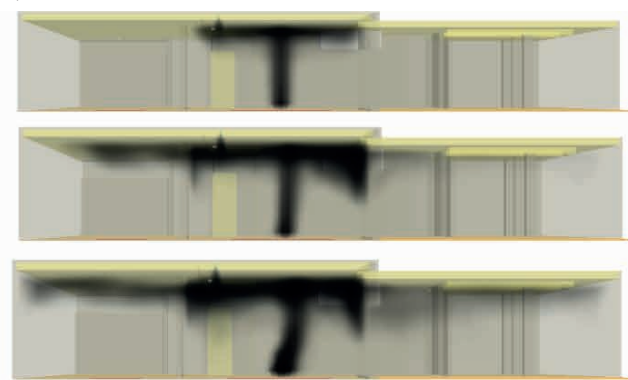

Fig. 2. Simulation of smoke spreading in a building - comparison of methods, a) analog simulation with salt water (inverted image), b) CFD computer simulation, Source: Own study based on [19]

The similarity criterion to fulfill and the corresponding scales can be obtained from equations describing a given phenomenon. Tests carried out on a suitably reduced model should be performed while maintaining the geometric similarity of the model in relation to the real object. It is also important to keep the other selected criteria of similarity of physical phenomena. The above idea is presented in Fig. 3.

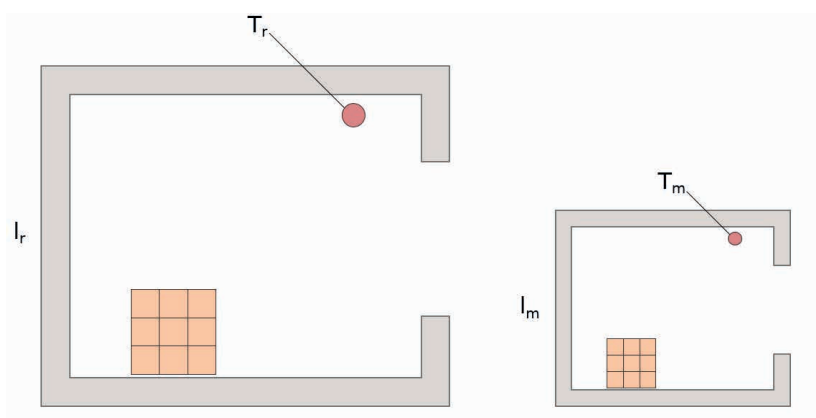

Fig. 3. Similarity of real and model scale. Source: Own study.

Fig. 3 shows two geometrically similar room. One on the real scale (left) with height $l_{r}$ and the other on the model scale (right) with height $l_{m}$. To maintain the similarity, the dimensions of all rooms and objects in the analyzed space must be changed. One should not forget about keeping proportional distances between e.g. measuring devices $\left(T_{r}\right.$ i $\left.T_{m}\right)$. For phenomena that occur during a fire, the basis for physical modeling is to maintain the Froude number.

The buoyancy force resulting from the difference in fluid density can be mapped in several way. They are presented in Table 2 . The buoyancy force arising during a fire and the work of fire ventilation are so dominant that the phenomenon of friction has a limited effect on the flow of smoke. Therefore, maintaining the Reynolds number (Table 2) is not required as long as $\operatorname{Re}>10,000$. This is a significant simplification of the research method, since the simultaneous maintenance of both Froude number and Reynolds number is extremely difficult and would require scaling kinematic viscosity of the fluid (e.g. smoke) and roughness of building partitions [14]. To be able to conduct research on a model scale, the criterion of similarity of the Froude number should be kept:

$$
F r_{m}=F r_{r}
$$


With the equations described in Table. 1 it is known that the Froude number describes the ratio of inertial force to the force of gravity. With its practical application, the mapping of the buoyant force can be implemented in several way. The first and easiest method is to generate heat in a certain amounts. It is important then to accurately calculate the rate of heat release using the formula (10). Other methods are implemented by using helium with air of a certain and known density [21], [22], or mixtures of water with varying degrees of salinity [19], [23]. Other values important for flow modeling in fire tests are additionally described by the equations presented in Table 2 .

Table 2. Relationships between model and real scale values. Source: Own study based on [14]

\begin{tabular}{llll}
\hline Parameter & Unit & Scale ratio & Number of equation \\
\hline Heat release rate & {$[\mathrm{kW}]$} & $\frac{Q_{m}}{Q_{r}}=\left(\frac{X_{m}}{X_{r}}\right)^{5 / 2}$ & $(10)$ \\
\hline Air flow rate & {$[\mathrm{m} / \mathrm{s}]$} & $\frac{V_{m}}{V_{r}}=\left(\frac{X_{m}}{X_{r}}\right)^{1 / 2}$ & $(11)$ \\
\hline Time & {$[\mathrm{s}]$} & $\frac{t_{m}}{t_{r}}=\left(\frac{X_{m}}{X_{r}}\right)^{3}$ & $(12)$ \\
\hline Energy & {$[\mathrm{kJ}]$} & $\frac{E_{m}}{E_{r}}=\left(\frac{X_{m}}{X_{r}}\right)^{3}$ & $(13)$ \\
\hline Mass change & {$[\mathrm{kg}]$} & $\frac{\dot{m}_{m}}{\dot{m}_{r}}=\left(\frac{X_{m}}{X_{r}}\right)^{3}$ & $(15)$ \\
\hline Temperature & {$[\mathrm{K}]$} & $T m=T r$ &
\end{tabular}

The formulas (10-15) presented in Table 2 describe the relationships between values on the model scale and the real scale. The $X_{r}$ parameter describes the real scale, and $X_{m}$ describes the model scale. For calculations from the 1: 1 scale to the 1: 2 scale, it will be $X_{r}=1$ and $X_{m}=2$, respectively. Parameters and formulas have been widely described and used in the work presented by Quintiere [14]. The equations collected in Tab. 2 are just some of the functions describing the scaling process. However, they are sufficient to carry out the tests underlying the fire tests on a model scale. More information on the dependencies used can be found in the works of Thomas, Quintiere and Morgan 'a [10], [24], [25].

\subsection{Application of the Froude number}

Modeling fires using Froude similitude is one of the most popular techniques for modeling fire phenomena. The roots of the method date back to the 1960s [26]. It was further developed in the following years. Practical significance is found wherever it is important to determine the relationships describing the flow of smoke in space [25], through openings [18], as well as to optimize fire ventilation systems [27]. In many cases, no research can be done without using the model scale. This is the case, for example, in experiments on road or rail tunnels [28] [29]. 
The basic issue before conducting experiments is the selection of the appropriate scale of the model for the studied phenomenon. This coefficient cannot be large enough so that the construction costs, time and complexity of the model approach those that occur at full scale. Generating large amounts of heat, which is a significant threat, may be an additional problem. On the other hand, the scale used may not be too small (e.g. 1: 100), because it is important to maintain the correlation between the real and the model phenomenon. In addition, the use of too small a model scale can create difficulties in finding the right measuring equipment. Table 3 presents a list of scales that were used in several experiments. The list contained in Table 3 presents only examples of quantities. It does not include all scales at which fire phenomena are tested.

Table 3. Examples of scale sizes used in fire test. Source: Own study

\begin{tabular}{lllll}
\hline No. & Scale size & Type of object & Number of tests & Source \\
\hline 1 & $1: 1$ & road tunnel & 5 & {$[4]$} \\
2 & $1: 2$ & railway wagon & 10 & {$[30]$} \\
3 & $1: 3$ & single-family housing estate & 2 & {$[7]$} \\
\hline 4 & $1: 7$ & room & 3 & {$[31]$} \\
\hline 5 & $1: 8$ & basement & 1 & {$[32]$} \\
\hline 6 & $1: 10$ & shopping mall & 48 & {$[6]$} \\
\hline 7 & $1: 15$ & road tunnel & 28 & {$[33]$} \\
\hline 8 & $1: 20$ & road tunnel & 54 & {$[34]$} \\
\hline 9 & $1: 23$ & road tunnel & 12 & {$[35]$} \\
\hline 10 & $1: 48$ & railway tunnel & 1 & {$[29]$} \\
\hline
\end{tabular}

Based on the analysis of the data presented in Table 3, one universal scale that could be adopted in the study cannot be determined. Often the same phenomenon is reproduced on several different scales. Each time the team conducting the experiment should assess on their own whether the scale used is appropriate for describing a given phenomenon. The choice of this or that scale also depends on the possibilities of using the measuring equipment owned or available space.

Choosing the right scale to conduct experiments is a very difficult task in itself. An additional obstacle deepening this problem may be the selection of appropriate measuring equipment. When choosing the right measuring instruments for model scale testing, there are two key issues to consider. In addition to the obvious justification for the use of a given instrumentation (the possibility of measuring the analyzed parameters), the size of this device should also be taken into account. For a full-scale test room (1:1 scale), the introduction of e.g. one or several thermocouples with a diameter of $1.5 \mathrm{~mm}$ will not affect the flow in the test space. However, if the same number of identical thermocouples is entered into the test-room model on a scale of 1: 100, it can have a real impact on the final results of the experiments.

An even bigger problem is the use of flow measurement tools - Prandtl tubes, thermo anemometers or bidirectional airflow probes. Due to their size and inaccurate measurements at threshold response values, the research capabilities on the model scale are decreasing. Laser imaging methods can solve these types of problems. These are relatively new methods that allow the simultaneous measurement of temperature (Digital Particle Image Thermometry, DPIT) and flow velocity (Digital Particle Image Velocimetry, DPIV) of particles in the analyzed space [36]. White light-illuminated particles have the ability to 
selectively disperse different colors depending on the ambient temperature. Recording this phenomenon using a suitable camera allows to determine the temperature of flowing particles. By comparing the displacement of individual particles on two frames / photos with a known time interval, their movement speed can be determined. In addition to accurate measurements, the advantage of these methods is the lack of need to place relatively large measuring devices in small test space. Thanks to this, the phenomena accompanying fire experiments are not disturbed.

\section{Summary}

Performing fire tests on a model scale is undoubtedly a huge source of information. It is often the only feasible way for an in-depth study and analysis of many physical phenomena. The results of many studies in recent years have lead to a better understand of the uncontrolled phenomenon of fire. The collected data is used to develop and continually improve CFD computer programs. Knowledge based on the experience drawn from the performed experiments allows to estimate the possible course of events in the event of a fire, and as a consequence - develop projects for more effective fire protection. That is why it is so important that the results obtained from the model scale correspond to the reality in which we - residents and users of secured buildings can find ourselves.

\section{References}

[1] Drysdale D., Fire safety by design: a framework for the future. Fire Safety Journal vol. 23, no 2, p. 113, 1994.

[2] Wegrzynski W., Sulik P., The philosophy of fire safety engineering in the shaping of civil engineering development. Bulletin of the Polish Academy of Sciences: Technical Sciences, vol. 64, no 4, p. 719-730, 2016.

[3] Cooper L.Y., Harkleroad M., Quintiere J., Rinkinen W. An experimental study of upper hot layer stratification in full-scale multiroom fire scenarios. Journal of Heat Transfer, vol. 104, no 4, p. 741, 2009.

[4] Li Y.Z., Ingason H., Lönnermark A. Runehamar Tunnel Fire Tests. Boras, 2011.

[5] Mehta S. Upholstered furniture fill scale chair tests - open flame ignition results and analysis. 2012.

[6] Węgrzyński W. Partitions and the flow of smoke in large volume buildings, Architecture, Civil Engineering, Environment, vol. 11, no 1, p. 155-164, 2019.

[7] Himoto K., Shinohara M., Sekizawa A., Takanashi K., Saiki H. A field experiment on fire spread within a group of model houses. Fire Safety Journal, vol. 96, no May 2017, p. 105-114, 2018.

[8] Krauze A., Fliszkiewicz M., Maciak T. Możliwości stosowania programów komputerowych w inżynierii bezpieczeństwa pożarowego. Bezpieczeństwo i Technika Pożarnicza, vol. 29, ed. 1, p. 47-60, 2013.

[9] Krasuski A., Pecio M. Application of an integrated risk assessment software to quantify the life safety risk in building during a fire. MATEC Web of Conferences, vol. 247, ed. 1, p. 11, 2018.

[10] Quintiere J.G. Scaling applications in fire research. Fire Safety Journal, vol. 15, ed. 1, p. 3-29, 1989.

[11] Vigne G., Węgrzyński W. Influence of variability of soot yield parameter in assessing the safe evacuation conditions in advanced modeling analysis. results of physical and numerical modeling comparison, [w:] $11^{\text {th }}$ Conference on Performance-Based Codes and Fire Safety Design Methods, 2016, ed. May, p. 14.

[12] Vigne G., Gutierrez-Montes C., Cantizano A., Węgrzyński W., Rein G. Review and validation of the current smoke plume entrainment models for large-volume buildings. Fire Technology, vol. 55, ed. 3, p. 789-816, 2019. 
[13] Wang X.Y., Spearpoint M.J., Fleischmann C.M. Comparison of results from large-scale and small-scale tunnel experiments. Fire Safety Journal, vol. 95, ed. August 2017, p. 135-144, 2018.

[14] Quintiere J.G. Fundamentals of fire phenomena. 2006.

[15] Zohuri B. Dimensional analysis and self-similarity methods for engineers and scientists. Springer US, 2015.

[16] Jezowiecka-Kabsch K., Szewczyk H. Fluid mechanics. Wrocław: Wrocław University of Technology Publishing House, 2001.

[17] Thomas P.H. Modelling of compartment fires, Fire Safety Journal, vol. 5, ed. 3-4, p. 181-190, 1983.

[18] Prahl J., Emmons H.W. Fire induced flow through an opening, Combustion and Flame, vol. 25, ed. C, p. 369-385, 1975.

[19] Steckler K.D., Baum H.R., Quintiere J.G. Salt water modeling of fire induced flows in a multiroom enclosure. Chemical and Physical Processes in Combustion, Fall Technical Meeting, The Eastern States Section, p. 143-149, 1985.

[20] Krasuski A., Krenski K. A-Evac: the evacuation simulator for stochastic environment. Fire Technology, 2019.

[21] Zhao G., Wang L. Using helium smoke as a surrogate of fire smoke for the study of atrium smoke filling. Journal of Fire Sciences, vol. 32, ed. 5, p. 431-447, 2014.

[22] Shanley J., i Beyler C. Horizontal vent flow modeling with helium and air. Fire Safety Science, vol. 2, p. 305-313, 1989.

[23] Yao X., Marshall A.W. Quantitative salt-water modeling of fire-induced flow. Fire Safety Journal, vol. 41, ed. 7, p. 497-508, 2006.

[24] Thomas P.H., Modelling of compartment fires. Fire Safety Journal, vol. 5, ed. 3-4, p. 181-190, 1983.

[25] Morgan H.P., De Smedt J.-C., Hot smoke tests: testing the design performance of smoke and heat ventilation systems and of impulse ventilation. International Journal on Engineering Performance-Based Fire Codes, vol. 6, ed. 1, p. 7-18, 2004.

[26] Thomas P.H., Hinkley P.L., Theobald C.R., Simms D.L. Investigations into the flow of hot gasses in roof venting. ed. 7. BRE, 1963.

[27] Wȩgrzyński W., Konecki M. Influence of the fire location and the size of a compartment on the heat and smoke flow out of the compartment, [w:] AIP Conference Proceedings, 2018, vol. 1922, ed. January, p. 12.

[28] Li Y.Z., Lei B., Ingason H. Study of critical velocity and backlayering length in longitudinally ventilated tunnel fires. Fire Safety Journal, vol. 45, ed. 6-8, p. 361-370, 2010.

[29] Kim D.H., Park W.H. Experiment by using reduced scale models for the fire safety of a rescue station in very long rail tunnel in Korea. Tunnelling and Underground Space Technology, vol. 21, ed. 3-4, p. 303, 2006.

[30] Lönnermark A., Lindström J., Li Y.Z. Model-scale metro car fire tests. Model-scale metro car fire tests of Sweden. SP Technical Research Institute of Sweden, 2011.

[31] Quintiere J., Mccaffrey J., Kashiwagi T. A scaling study of a corridor subject to a room fire. Combustion Science and Technology, vol. 18, ed. 1-2, p. 1-19, 1978.

[32] Arini D., Pancawardani F., Santoso M.A., Sugiarto B., Nugroho Y.S. Froude modelling of fire phenomena: observation of fire-induced smoke movement in basement structure for firefighting purpose. Procedia Engineering, vol. 170, p. 182-188, 2017.

[33] Li Y.Z., Ingason H. Model scale tunnel fire tests with automatic sprinkler. Fire Safety Journal, vol. 61, p. 298-313, 2013.

[34] Li Y.Z., Lei B., Ingason H. Scale modeling and numerical simulation of smoke control for rescue stations in long railway tunnels. Journal of Fire Protection Engineering, vol. 22, ed. 2, p. 101-131, 2012.

[35] Ingason H., Li Y.Z. Model scale tunnel fire tests with longitudinal ventilation. Fire Safety Journal, vol. 45, ed. 6-8, p. 371-384, 2010.

[36] Dabiri D. Digital particle image thermometry/velocimetry: A review. Experiments in Fluids, vol. 46, ed. 2, p. 191-241, 2009. 